\title{
ABSOLUTE SUMMABILITY OF A FOURIER SERIES AND ITS DERIVED SERIES BY A PRODUCT METHOD
}

\author{
H. P. DIKSHIT
}

(Received 29 July 1970)

Communicated by $\mathbf{B}$. Mond

\section{Definitions and notations}

Let $\Sigma a_{n}$ be a given infinite series with the sequence of partial sums $\left\{s_{n}\right\}$. Let $\left\{p_{n}\right\}$ be a sequence of constants, real or complex, and let us write $P_{n}=p_{0}+p_{1}+\cdots+p_{n} ; P_{-1}=p_{-1}=0$.

The sequence to sequence transformation

$$
t_{n}=\sum_{k=0}^{n} p_{n-k} s_{k} / P_{n}=\sum_{k=0}^{n} P_{n-k} a_{k} / P_{n} ;\left(P_{n} \neq 0\right)
$$

defines the sequence $\left\{t_{n}\right\}$ of Nörlund means [11] of the sequence $\left\{s_{n}\right\}$, generated by the sequence of coefficients $\left\{p_{n}\right\}$. The series $\Sigma a_{n}$ is said to be summable $\left(N, p_{n}\right)$ to the sum $s$ if $\lim _{n \rightarrow \infty} t_{n}$ exists and is equal to $s$, and is said to be absolutely summable $\left(N, p_{n}\right)$ or summable $\left|N, p_{n}\right|$, if the sequence $\left\{t_{n}\right\}$ is of bounded variation, that is, the infinite series $\Sigma_{n}\left|t_{n}-t_{n-1}\right|<\infty$ (symbolically, $\left\{t_{n}\right\} \in \mathrm{BV}$ ) [10]. In the special case in which

$$
p_{n}=\left(\begin{array}{c}
n+\delta-1 \\
\delta-1
\end{array}\right)=\frac{\Gamma(n+\delta)}{\Gamma(n+1) \Gamma(\delta)}(\delta>-1)
$$

the Nörlund mean reduces to the familiar $(C, \delta)$ mean. Thus the summability $\left|N, p_{n}\right|$ is the same as $|C, \delta|$ if $\left\{p_{n}\right\}$ is defined by (1.2).

The $\left(N, p_{n}\right)(C, 1)$ mean of $\left\{s_{n}\right\}$ is defined as the $\left(N, p_{n}\right)$ mean of the sequence of $(C, 1)$ means of $\left\{s_{n}\right\}$. We write $t_{n}^{1}$ for the $\left(N, p_{n}\right)(C, 1)$ mean of $\left\{s_{n}\right\}$. Thus

$$
t_{n}^{1}=\frac{1}{P_{n}} \sum_{k=0}^{n} p_{n-k} \frac{1}{k+1} \sum_{v=0}^{k} s_{v} .
$$

The series $\Sigma a_{n}$ is said to be summable $\left(N, p_{n}\right)(C, 1)$ to the sum $t$, if $\lim _{n \rightarrow \infty} t_{n}^{1}$ exists and is equal to $t$ and is said to be absolutely summable $\left(N, p_{n}\right)(C, 1)$ or summable $\left|\left(N, p_{n}\right)(C, 1)\right|$, if $\left\{t_{n}^{1}\right\} \in \mathrm{BV}$.

The conditions 


$$
\lim _{n \rightarrow \infty} p_{n} / P_{n}=0 \text { and } \sum_{k=0}^{n}\left|p_{k}\right|=O\left(\left|P_{n}\right|\right), n \rightarrow \infty ;
$$

are necessary and sufficient for the regularity of the $\left(N, p_{n}\right)$ mean, while the conditions:

$$
\left\{P_{n} / P_{n+k}\right\} \in \mathrm{BV}, \text { for any } k \geqq 1 \text { and } p_{n-k} / P_{n}=o(1), n \rightarrow \infty, \text { for some fixed } k
$$

are necessary and sufficient for its absolute regularity [9].

Let $f(t)$ be a periodic function with period $2 \pi$ and integrable $(L)$ over $(-\pi, \pi)$. We assume without any loss of generality that the constant term in the Fourier series of $f(t)$ is zero, so that

and

$$
\int_{-\pi}^{\pi} f(t) d t=0
$$

$$
f(t) \sim \sum_{n=1}^{\infty}\left(a_{n} \cos n t+b_{n} \sin n t\right)=\sum_{n=1}^{\infty} A_{n}(t) .
$$

The derived series of (1.5) is

$$
\sum_{n=1}^{\infty} n\left(b_{n} \cos n t-a_{n} \sin n t\right) .
$$

We write throughout:

$$
\begin{aligned}
& \phi(t)=\frac{1}{2}\{f(x+t)+f(x-t)\} ; \psi(t)=\frac{1}{2}\{f(x+t)-f(x-t)\} ; \\
& \Phi_{\alpha}(t)= \frac{1}{\Gamma(\alpha)} \int_{0}^{t}(t-u)^{\alpha-1} \phi(u) d u, \alpha>0 ; \Phi_{0}(t)=\phi(t) ; \\
& \phi_{\alpha}(t)=\Gamma(\alpha+1) t^{-\alpha} \Phi_{\alpha}(t), \alpha \geqq 0 ; g(t)=\psi(t) / t ; \\
& P_{n}^{*}=\sum_{k=0}^{n}\left|p_{k}\right| ; R_{n}=(n+1) p_{n} / P_{n} ; \\
& S_{n}=\sum_{k=0}^{n}(k+1)^{-1} P_{k} / P_{n} ; S_{n}^{*}=\sum_{k=0}^{n}(k+1)^{-1}\left|P_{k}\right| / P_{n} ; \\
& \Delta f_{n}=\Delta_{n} f_{n}=f_{n}-f_{n+1} ; V_{n}=\sum_{k=0}^{n} k\left|\Delta p_{k-1}\right| / P_{n} ; \\
& \lambda_{k}(t)=\sum_{r=0}^{k} \sin (r t) / k(k+1) ;
\end{aligned}
$$

$[m]$ denotes the greatest integer not greater than $m$. In particular we write $\tau=[\pi / t]$.

By ' $F(t) \in \operatorname{BV}(a, b)$ ', we mean that $F(t)$ is a function of bounded variation in the interval $(a, b)$ and by ' $\left\{f_{n}\right\} \in B$ ' that $\left\{f_{n}\right\}$ is a bounded sequence.

$K$ denotes a positive constant, not necessarily the same at each occurrence. 


\section{Introduction}

Concerning the $|C|$ summability of the Fourier series (1.5), Bosanquet [2] has proved the following.

TheOREM A. If $\phi_{\alpha}(t) \in \mathrm{BV}(0, \pi)$, then the Fourier series of $f(t)$ at $t=x$, is summable $|C, \alpha+\delta|$ for every $\delta>0$.

A generalisation of Theorem A when $\alpha=0$ to $\left|N, p_{n}\right|$ summability is the following result of Pati [12].

THEOREM B. If $\phi(t) \in \mathrm{BV}(0, \pi)$ and $\left\{p_{n}\right\}$ is a nonnegative monotonic nonincreasing sequence such that $\left\{R_{n}\right\} \in \mathrm{BV},\left\{S_{n}\right\} \in \mathrm{BV}$, then the Fourier series of $f(t)$, at $t=x$, is summable $\left|N, p_{n}\right|$.

Theorem B for more general sequences $\left\{p_{n}\right\}$ has been obtained by Pati [13] Varshney [15], Dikshit [3], [5] and Si-Lei [14].

For the $\left(N, p_{n}\right)(C, 1)$ method Astrachan [1] has proved the following.

THEOREM C. The $\left(N, p_{n}\right)(C, 1)$ method is $K_{\alpha}$-effective $(0<\alpha \leqq 1)$, provided the sequence $\left\{p_{n}\right\}$ satisfies the conditions (i) $\left\{R_{n}\right\} \in B$, (ii) $\left\{V_{n}\right\} \in B$ and (iii) $\left\{S_{n}^{*}\right\} \in B$.

That the $\left(N, p_{n}\right)$ mean used in Theorem $\mathrm{C}$ satisfies the regularity conditions (1.3), is apparent from the following.

$$
\begin{aligned}
P_{n}^{*} & =\sum_{k=0}^{n}\left|p_{n}+\sum_{\mu=k}^{n-1} \Delta p_{\mu}\right|^{\dagger} \\
& \leqq(n+1)\left|p_{n}\right|+\sum_{k=0}^{n-1} \sum_{\mu=k}^{n-1}\left|\Delta p_{\mu}\right| \\
& =\left|P_{n} R_{n}\right|+\sum_{\mu=0}^{n-1}(\mu+1)\left|\Delta p_{\mu}\right| \\
& =O\left(\left|P_{n}\right|\right),
\end{aligned}
$$

by virtue of the hypotheses (i) and (ii) of Theorem $\mathrm{C}$, the former of which implies that $p_{n} / P_{n}=o(1), n \rightarrow \infty$.

Thus, Astrachan's use of the regularity conditions in his proof of Theorem $C$ is justified. It may also be observed that the hypothesis ' $\left\{p_{n}\right\}$ is a regular sequence' may as well be dropped from the statements of some earlier results due to Hille and Tamarkin ([6], Theorem I) and Astrachan [1]. In [4] the present author has indicated and supplied a deficiency in the proof of Theorem C.

Theorem $\mathrm{C}$ implies inter alia that the Fourier series of $f(t)$ is summable

$\dagger$ Throughout the present paper $\Sigma_{a}^{b}$ will be taken as zero if $a>b$. 
$\left(N, p_{n}\right)(C, 1)$ at every point $t=x$, at which $\lim _{t \rightarrow 0} \phi_{1}(t)=f(x)$, provided the sequence $\left\{p_{n}\right\}$ satisfies the hypotheses of the theorem.

Since generally bounded variation is the property associated with absolute summability in the same sense in which continuity is associated with ordinary summability, it is natural to expect from Theorem $\mathrm{C}$ that the condition $\phi_{1}(t) \in \mathrm{BV}(0, \pi)$, along with the bounded variation of sequences in (i), (ii) and (iii) may be sufficient to ensure the $\left|\left(N, p_{n}\right)(C, 1)\right|$ summability of the Fourier series of $f(t)$, at $t=x$. Further, since the $\left|\left(N, p_{n}\right)(C, 1)\right|$ with $\left\{p_{n}\right\}$ defined by (1.2) is the same as $|C, 1+\delta|$, Theorem $\mathbf{A}$ and Theorem $\mathbf{B}$ also suggest that the condition $\phi_{1}(t) \in \mathrm{BV}(0, \pi)$ along with the hypotheses of Theorem $\mathrm{B}$, concerning $\left\{p_{n}\right\}$ may lead to the $\left|\left(N, p_{n}\right)(C, 1)\right|$ summability of the Fourier series of $f(t)$, at $t=x$. That, this is indeed true for a more general sequence $\left\{p_{n}\right\}$ is established by our Theorem 1 , which contains as a special case Theorem $\mathrm{A}$ for $\alpha=1$, when we observe that the $(C, \delta)$ mean is a special case of the $\left(N, p_{n}\right)$ mean and appeal to a result of Kogbetliantz [8].

In Theorem 2 we obtain a result for the $\left|\left(N, p_{n}\right)(C, 1)\right|$ summability of the derived series, which includes the following form of a result due to Hyslop [7].

THEOREM D. If $g(t) \in \operatorname{BV}(0, \pi)$, then the derived series of the Fourier series of $f(t)$, at $t=x$, is summable $|C, 1+\delta|$ for every $\delta>0$.

\section{Main results}

We prove the following.

THEOREM 1. If $\phi_{1}(t) \in \mathrm{BV}(0, \pi)$ and $\left\{p_{n}\right\}$ is any sequence such that $P_{n}^{*}=O\left(\left|P_{n}\right|\right)$, $\left\{R_{n}\right\} \in \mathrm{BV}$ and $\left\{S_{n}\right\} \in \mathrm{BV}$, then the Fourier series of $f(t)$ at $t=x$, is summable $\left|\left(N, p_{n}\right)(C, 1)\right|$.

THEOREM 2. If $g(t) \in \mathrm{BV}(0, \pi)$ and $\left\{p_{n}\right\}$ satisfies the hypotheses of Theor $m 1$, then the derived series (1.6), at $t=x$ is summable $\left|\left(N, p_{n}\right)(C, 1)\right|$.

\section{Some preliminary results}

We require the following lemmas for the proof of our theorems

LEMMA 1. If $\left\{p_{n}\right\}$ is any sequence such that $P_{n}^{*}=O\left(\left|P_{n}\right|\right),\left\{R_{n}\right\} \in \mathrm{BV}$ and $\left\{S_{n}\right\} \in \mathrm{BV}$, then $\left\{V_{n}\right\} \in B$.

Lemma 1 is the same as Theorem 2 of [5].

Lemma 2. If $\left\{p_{n}\right\}$ satisfies the conditions $P_{n}^{*}=O\left(\left|P_{n}\right|\right),\left\{R_{n}\right\} \in \mathrm{BV}$ and $\left\{S_{n}\right\} \in \mathrm{BV}$, then uniformly in $0<t \leqq \pi$

$$
\sum_{n=1}^{\infty}\left|\frac{1}{P_{n} \bar{P}_{n-1}} \sum_{k=0}^{n-1}\left(P_{n} p_{k}-p_{n} P_{k}\right) \frac{\sin \left(n-k+\frac{1}{2}\right) t}{n-k+\frac{1}{2}}\right| \leqq K .
$$


PROOF. The lemma follows from Lemma 1, when one observes that the proof of (4.1) is similar to the proof of the following ([14], p. 284)

$$
\sum_{n=1}^{\infty}\left|\frac{1}{P_{n} P_{n-1}} \sum_{k=0}^{n-1}\left(P_{n} p_{k}-p_{n} P_{k}\right) \frac{\sin (n-k) t}{n-k}\right| \leqq K .
$$

LEMMA 3. If $\theta(t) \in \operatorname{BV}(0, \pi)$ and $\left\{p_{n}\right\}$ is any sequence such that $P_{n}^{*}=O\left(\left|P_{n}\right|\right)$, $\left\{R_{n}\right\} \in \mathrm{BV}$ and $\left\{S_{n}\right\} \in \mathrm{BV}$, then the sequence $\left\{u_{n}\right\}$, where

is summable $\left|N, p_{n}\right|$.

$$
u_{n}=\int_{0}^{\pi} \theta(t) \frac{\sin (n+1) t}{\sin \frac{1}{2} t} d t
$$

PRoOF. Following the proof of a theorem of Pati ([12], p.156), we observe that if $\theta(t) \in \operatorname{BV}(0, \pi)$, then in order to prove the $\left|N, p_{n}\right|$ summability of $\left\{u_{n}\right\}$ it is sufficient to show that (4.1) holds, uniformly in $0<t \leqq \pi$. Thus Lemma 3 follows from Lemma 2.

Lemma 4. Uniformly in $0<t \leqq \pi$ and for any positive integer $n$

$$
\left|\sum_{k=1}^{n} \lambda_{k}(t)\right| \leqq K
$$

Proof. By a change of order of summation, we have

$$
\begin{aligned}
\sum_{k=1}^{n} \frac{1}{k(k+1)} \sum_{v=1}^{k} \sin v t & =\sum_{v=1}^{n} \sin v t \sum_{k=v}^{n}\left(\frac{1}{k}-\frac{1}{k+1}\right) \\
& =\sum_{v=1}^{n} \frac{\sin v t}{v}-\frac{1}{n+1} \sum_{v=1}^{n} \sin v t
\end{aligned}
$$

The lemma follows from this when we observe that $\left|\sum_{v=1}^{n} \frac{\sin v t}{v}\right| \leqq K$.

Lemma 5. If $0 \leqq v<n$, then uniformly in $0<t \leqq \pi$

$$
\left|\sum_{k=0}^{v} P_{k} \lambda_{n-k}(t)\right| \leqq K P_{v}^{*} \text {. }
$$

Proof. Applying Abel's transformation, we get

$$
\begin{aligned}
\left|\sum_{k=0}^{v} P_{k} \lambda_{n-k}(t)\right| & \leqq \sum_{k=0}^{v-1}\left|p_{k+1}\right|\left|\sum_{r=0}^{k} \lambda_{n-r}(t)\right|+\left|P_{v}\right|\left|\sum_{r=0}^{v} \lambda_{n-r}(t)\right| \\
& \leqq K P_{v}^{*},
\end{aligned}
$$

by virtue of Lemma 4 .

Lemma 6. For any sequence $\left\{p_{n}\right\}$ such that $P_{n}^{*}=O(|P|),\left\{S_{n}\right\} \in \mathrm{BV}$ implies that $\left\{S_{n}^{*}\right\} \in B$. 
Lemma 6 is the same as Lemma 2 of [5].

Lemma 7. If $\left\{p_{n}\right\}$ is any sequence such that $P_{n}^{*}=O\left(\left|P_{n}\right|\right)$, then $\left\{S_{n}\right\} \in \mathrm{BV}$ implies that

$$
\left|P_{k}\right| \sum_{n=k+1}^{\infty} \frac{1}{n\left|P_{n-1}\right|} \leqq K
$$

where $k=0,1,2, \cdots$.

Proof. Since $P_{n}^{*}=O\left(\left|P_{n}\right|\right)$, we have for an integer $M>k$

$$
\begin{aligned}
& \left|P_{k}\right| \sum_{n=k+1}^{M} \frac{1}{n\left|P_{n-1}\right|} \\
& \leqq K\left|P_{k}\right| \sum_{n=k+1}^{M} \frac{\left|P_{n-1}\right|}{n}\left(\frac{1}{P_{n-1}^{*}}\right)^{2} \\
& \leqq K\left|P_{k}\right| \sum_{n=k+1}^{M-1}\left\{\frac{1}{\left(P_{n-1}^{*}\right)^{2}}-\frac{1}{\left(P_{n}^{*}\right)^{2}}\right\} \sum_{v=1}^{n} \frac{\left|P_{v-1}\right|}{v} \\
& +K\left|P_{k}\right|\left(\frac{1}{P_{k}^{*}}\right)^{2} \sum_{v=1}^{k+1} \frac{\left|P_{v-1}\right|}{v}+K \frac{\left|P_{k}\right|}{\left(P_{M^{-1}}^{*}\right)^{2}} \sum_{v=1}^{M} \frac{\left|P_{v-1}\right|}{v} \\
& \leqq K\left|P_{k}\right| \sum_{n=k+1}^{M-1} \frac{\left(P_{n}^{*}+P_{n-1}^{*}\right)}{\left(P_{n}^{*}\right)^{2} P_{n-1}^{*}}\left|p_{n}\right| S_{n-1}^{*}+K S_{k}^{*}+K S_{M-1}^{*} \\
& \leqq K\left|P_{k}\right| \sum_{n=k+1}^{M-1} \frac{1}{P_{n}^{*} P_{n-1}^{*}}\left|p_{n}\right|+K \\
& =K\left|P_{k}\right| \sum_{n=k+1}^{M-1}\left(\frac{1}{P_{n-1}^{*}}-\frac{1}{P^{*}}\right)+K \leqq K, \text { as } M \rightarrow \infty \text {, }
\end{aligned}
$$

since by Lemma $6,\left\{S_{n}^{*}\right\} \in B$. This completes the proof of the lemma.

Lemma 8. For $k \geqq 1$ and uniformly in $0<t \leqq \pi$, we have

$$
\lambda_{k}(t)=\left\{\begin{array}{l}
O(t), \\
O\left(k^{-2} \tau\right) .
\end{array}\right.
$$

Proof. Since $|\sin v t| \leqq v t$, we have

$$
\left|\lambda_{k}(t)\right| \leqq t \sum_{v=1}^{k} \frac{v}{k(k+1)} \leqq K t,
$$

which proves (4.2). (4.3) follows directly from the fact that $\Sigma_{v=1}^{k} \sin v t=O(\tau)$. 
LEMMA 9. If $\theta(t) \in \operatorname{BV}(0, \pi)$ and $\left\{p_{n}\right\}$ is any sequence such that $P_{n}^{*}=O\left(\left|P_{n}\right|\right)$, $\left\{R_{n}\right\} \in \mathrm{BV}$ and $\left\{S_{n}\right\} \in \mathrm{BV}$, then the sequence $\left\{v_{n}\right\}$, where

$$
v_{n}=\frac{1}{n+1} \int_{0}^{\pi} \theta(t)\left\{\sin \frac{1}{2}(n+1) t / \sin \frac{1}{2} t\right\}^{2} d t
$$

is summable $\left|N, p_{n}\right|$.

ProOf. We write

$$
\begin{aligned}
t_{n}-t_{n-1} & =\sum_{k=0}^{n}\left(\frac{p_{k}}{P_{n}}-\frac{p_{k-1}}{P_{n-1}}\right) v_{n-k} \\
& =\sum_{k=0}^{n-1} \Delta_{k} v_{n-k} \sum_{v=0}^{k}\left(\frac{p_{v}}{P_{n}}-\frac{p_{v-1}}{P_{n-1}}\right) \\
& =\frac{1}{P_{n} P_{n-1}} \sum_{k=0}^{n-1}\left(P_{n} p_{k}-p_{n} P_{k}\right) \Delta_{k} v_{n-k} .
\end{aligned}
$$

Since

$$
\left\{\sin \frac{1}{2}(n+1) t / \sin \frac{1}{2} t\right\}^{2}=\sum_{k=0}^{n}\left\{\sin \left(k+\frac{1}{2}\right) t / \sin \frac{1}{2} t\right\},
$$

we have by a well known identity due to Kogbetliantz [8]

$$
\begin{aligned}
v_{k}-v_{k-1} & =\frac{2}{k(k+1)} \int_{0}^{\pi} \theta(t)\left\{\sum_{r=1}^{k} r \cos r t\right\} d t \\
& =-\frac{2}{k(k+1)} \int_{0}^{\pi}\left\{\sum_{r=1}^{k} \sin r t\right\} d \theta(t) .
\end{aligned}
$$

Thus

$t_{n}-t_{n-1}=-2 \int_{0}^{\pi}\left\{\frac{1}{P_{n} P_{n-1}} \sum_{k=0}^{n-1}\left(P_{n} p_{k}-p_{n} P_{k}\right) \frac{1}{(n-k)(n-k+1)} \sum_{r=1}^{n-k} \sin r t\right\} d \theta(t)$.

Since by hypothesis $\int_{0}^{\pi}|d \theta(t)| \leqq K$, in order to show that $\Sigma_{n}\left|t_{n}-t_{n-1}\right|<\infty$, it is sufficient to demonstrate that uniformly in $0<t \leqq \pi$

$$
\Sigma \equiv \sum_{n}\left|\frac{1}{P_{n} P_{n-1}} \sum_{k=0}^{n-1}\left(P_{n} p_{k}-p_{n} P_{k}\right) \lambda_{n-k}(t)\right| \leqq K .
$$

We write

$$
\begin{aligned}
\Sigma \leqq & \sum_{n=1}^{\infty}\left|\frac{1}{(n+1) P_{n} P_{n-1}} \sum_{k=0}^{n-1}\left\{P_{n} p_{k}(k+1)-p_{n}(n+1) P_{k}\right\} \lambda_{n-k}(t)\right| \\
& +\sum_{n=1}^{\infty}\left|\frac{1}{(n+1) P_{n-1}} \sum_{k=0}^{n-1} p_{k}(n-k) \lambda_{n-k}(t)\right| \\
= & \sum_{1}+\sum_{2},
\end{aligned}
$$

say. 
Now

$$
\begin{aligned}
\Sigma_{1} & \leqq \sum_{n=1}^{\infty} \frac{1}{(n+1)\left|P_{n-1}\right|}\left|\sum_{k=0}^{n-1}\left(R_{k}-R_{n}\right) P_{k} \lambda_{n-k}(t)\right| \\
& =\sum_{n=1}^{\infty} \frac{1}{(n+1)\left|P_{n-1}\right|}\left|\sum_{k=0}^{n-1} P_{k} \lambda_{n-k}(t) \sum_{v=k}^{n-1} \Delta R_{v}\right| \\
& =\sum_{n=1}^{\infty} \frac{1}{(n+1)\left|P_{n-1}\right|} \sum_{v=0}^{n-1} \Delta R_{v} \sum_{k=0}^{v} P_{k} \lambda_{n-k}(t) \mid \\
& \leqq K \sum_{n=1}^{\infty} \frac{1}{(n+1)\left|P_{n-1}\right|} \sum_{v=0}^{n-1}\left|\Delta R_{v}\right| P_{v}^{*} \\
& \leqq K \sum_{v=0}^{\infty}\left|\Delta R_{v}\right|\left|P_{v}\right| \sum_{n=v+1}^{\infty} \frac{1}{(n+1)\left|P_{n-1}\right|} \\
& \leqq K \sum_{v=0}^{\infty}\left|\Delta R_{v}\right| \leqq K,
\end{aligned}
$$

by virtue of the hypothesis $\left\{R_{n}\right\} \in \mathrm{BV}$ and Lemma 7 .

We next write

$$
\begin{aligned}
\Sigma_{2} & =\sum_{n=1}^{\infty}\left|\frac{1}{(n+1) P_{n-1}} \sum_{k=1}^{n} k p_{n-k} \lambda_{k}(t)\right| \\
& \leqq \sum_{n=1}^{2 \tau+1} \frac{1}{(n+1)\left|P_{n-1}\right|} \sum_{k=1}^{n} k\left|p_{n-k}\right|\left|\lambda_{k}(t)\right|
\end{aligned}
$$

$$
\begin{aligned}
& +\sum_{n=2 \tau+2}^{\infty} \frac{1}{(n+1)\left|P_{n-1}\right|}\left\{\sum_{k=1}^{\tau}+\sum_{k=\tau+1}^{[n / 2]}+\sum_{k=[n / 2]+1}^{n}\right\} k\left|p_{n-k}\right|\left|\lambda_{k}(t)\right| \\
& =\sum_{21}+\sum_{22}+\sum_{23}+\sum_{24},
\end{aligned}
$$

say.

Since by Lemma $8, \lambda_{k}(t)=O(t)$, we have

$$
\Sigma_{21} \leqq K t \sum_{n=1}^{2 \tau+1} \frac{1}{\left|P_{n-1}\right|} \sum_{k=1}^{n}\left|p_{n-k}\right| \leqq K t \sum_{n=1}^{2 \tau+1} 1 \leqq K,
$$

by virtue of the hypothesis that $P_{n}^{*}=O\left(\left|P_{n}\right|\right)$.

We next note that, by the boundedness of $\left\{R_{n}\right\}$ and the assumption that $P_{n}^{*}=O\left(\left|P_{n}\right|\right)$, we have for $1 \leqq k \leqq \frac{1}{2} n$

$$
\left|p_{n-k}\right| \leqq K \frac{\left|P_{n-k}\right|}{n-k+1} \leqq K \frac{P_{n-k}^{*}}{n} \leqq K \frac{P_{n-1}^{*}}{n} \leqq K \frac{\left|P_{n-1}\right|}{n}
$$

By (4.2) and (4.8), we have

$$
\Sigma_{22} \leqq K t \sum_{n=2 \tau+2}^{\infty} \frac{1}{(n+1)^{2}} \sum_{k=1}^{\tau} k=K \tau \sum_{n=2 \tau+2}^{\infty} \frac{1}{(n+1)^{2}} \leqq K
$$


Further, by (4.3) and (4.8), we have

$$
\begin{aligned}
\Sigma_{23} & \leqq K \tau \sum_{n=2 \tau+2}^{\infty} \frac{1}{(n+1)^{2}} \sum_{k=\tau+1}^{[n / 2]} \frac{1}{k} \\
& \leqq K \tau \sum_{k=\tau+1}^{\infty} \frac{1}{k} \sum_{n=2 k}^{\infty} \frac{1}{(n+1)^{2}} \\
& \leqq K \tau \sum_{k=\tau+1}^{\infty} \frac{1}{k(k+1)} \leqq K .
\end{aligned}
$$

Finally, since, for relevant values of the variables $1 / k \leqq 2 /(n+1)$, it follows from (4.3) that

$$
\begin{aligned}
\sum_{24} & \leqq K \tau \sum_{n=2 \tau+2}^{\infty} \frac{1}{(n+1)^{2}\left|P_{n-1}\right|} \sum_{k=[n / 2]+1}^{n}\left|p_{n-k}\right| \\
& \leqq K \tau \sum_{n=2 \tau+2}^{\infty} \frac{1}{(n+1)^{2}} \leqq K,
\end{aligned}
$$

by virtue of the assumption that $P_{n}^{*}=O\left(\left|P_{n}\right|\right)$.

Combining (4.4)-(4.7) and (4.9)-(4.11), we demonstrate that $\Sigma \leqq K$, and this completes the proof of the Lemma.

LEMMA 10. If $\left\{p_{n}\right\}$ is any sequence such that $P_{n}^{*}=O\left(\left|P_{n}\right|\right),\left\{R_{n}\right\} \in \mathrm{BV}$ and $\left\{S_{n}\right\} \in \mathrm{BV}$, then the $\left(N, p_{n}\right)$ mean is absolutely regular.

Proof. In order to show that $\left\{P_{n} / P_{n+v}\right\} \in \mathrm{BV}$, for any $v \geqq 1$, we write

$$
\begin{aligned}
\Sigma^{*} \equiv \sum_{n=0}^{\infty}\left|\frac{P_{n}}{P_{n+v}}-\frac{P_{n-1}}{P_{n+v-1}}\right| & =\sum_{n=0}^{\infty}\left|\frac{P_{n}}{P_{n+v-1}}\right|\left|\frac{p_{n}}{P_{n}}-\frac{p_{n+v}}{P_{n+v}}\right| \\
& \leqq \sum_{n=0}^{\infty}\left|\frac{P_{n}}{P_{n+v-1}}\right| \sum_{k=n}^{n+v-1}\left|\Delta\left(\frac{R_{k}}{k+1}\right)\right|
\end{aligned}
$$

Writing $\mu_{n}=\left|P_{n}\right| P_{n+v-1} \mid$ and $\delta_{k}=\left|\Delta\left\{R_{k} /(k+1)\right\}\right|$, we have

$$
\begin{aligned}
\Sigma^{*} & \leqq \sum_{n=0}^{\infty} \mu_{n} \sum_{k=n}^{n+v-1} \delta_{k} \\
& =\sum_{n=0}^{v-1} \mu_{n}\left\{\sum_{k=n}^{v-1}+\sum_{k=v}^{n+v-1}\right\} \delta_{k}+\sum_{n=v}^{\infty} \mu_{n}\left\{\sum_{k=v}^{n+v-1}-\sum_{k=v}^{n-1}\right\} \delta_{k} \\
& =\sum_{k=0}^{v-1} \delta_{k} \sum_{n=0}^{k} \mu_{n}+\sum_{n=1}^{\infty} \mu_{n} \sum_{k=v}^{n+v-1} \delta_{k}-\sum_{n=v+1}^{\infty} \mu_{n} \sum_{k=v}^{n-1} \delta_{k} \\
& =\sum_{k=0}^{v-1} \delta_{k} \sum_{n=0}^{k} \mu_{n}+\sum_{k=0}^{\infty} \delta_{k+v} \sum_{n=k+1}^{\infty} \mu_{n}-\sum_{k=v}^{\infty} \delta_{k} \sum_{n=k+1}^{\infty} \mu_{n}
\end{aligned}
$$




$$
\begin{aligned}
= & \sum_{k=0}^{v-1}\left|\Delta\left(\frac{R_{k}}{k+1}\right)\right| \sum_{n=0}^{k}\left|\frac{P_{n}}{P_{n+v-1}}\right| \\
& +\sum_{k=v}^{\infty}\left|\Delta\left(\frac{R_{k}}{k+1}\right)\right| \sum_{n=k-v+1}^{k}\left|\frac{P_{n}}{P_{n+v-1}}\right| \\
(4.12)= & \Sigma_{1}^{*}+\Sigma_{2}^{*},
\end{aligned}
$$

say.

Now by assumption $P_{n}^{*}=O\left(\left|P_{n}\right|\right)$, we have

$$
\begin{aligned}
\Sigma_{1}^{*} & \leqq K \sum_{k=0}^{v-1}\left\{\frac{\left|\Delta R_{k}\right|}{k+1}+\frac{\left|R_{k+1}\right|}{(k+1)^{2}}\right\} \sum_{n=0}^{k} \frac{P_{n}^{*}}{P_{n+v-1}^{*}} \\
& \leqq \frac{K}{P_{\substack{*-1 \\
v-1}}^{v-1}} \sum_{k=0}^{v-1}\left|\Delta R_{k}\right| P_{k}^{*}+\frac{K}{P_{v-1}^{*}} \sum_{k=0}^{v-1} \frac{\left|P_{k}\right|}{k+1} \\
& \leqq K \sum_{k=0}\left|\Delta R_{k}\right|+K S_{v-1}^{*} \leqq K,
\end{aligned}
$$

by virtue of Lemma 6 and the assumption that $\left\{R_{n}\right\} \in \mathrm{BV}$.

Similarly,

$$
\begin{aligned}
\Sigma_{2}^{*} & \leqq K \sum_{k=v}^{\infty}\left\{\frac{\left|\Delta R_{k}\right|}{(k+1)}+\frac{\left|R_{k+1}\right|}{(k+1)^{2}}\right\} \sum_{n=k-v+1}^{k} \frac{P_{n}^{*}}{P_{n+v-1}^{*}} \\
& \leqq K v \sum_{k=v}^{\infty} \frac{\left|\Delta R_{k}\right|}{k+1}+K v \sum_{k=v}^{\infty} \frac{1}{(k+1)^{2}} \leqq K
\end{aligned}
$$

since $\left\{R_{n}\right\} \in \mathrm{BV}$.

Combining (4.12)-(4.14), we prove that $\left\{P_{n} / P_{n+v}\right\} \in \mathrm{BV}$, for any $y \geqq 1$.

Finally, since $P_{n}^{*}=O\left(\left|P_{n}\right|\right)$, we have as $n \rightarrow \infty$,

$$
p_{n-v} / P_{n}=O\left[\left|P_{n-v} /\left\{(n-v+1) P_{n}\right\}\right|\right]=o\left(P_{n-v}^{*} / P_{n}^{*}\right)=o(1),
$$

by virtue of the assumption that $\left\{R_{n}\right\} \in \mathrm{BV}$.

Thus the conditions (1.4) are satisfied and the $\left(N, p_{n}\right)$ mean is absolutely regular.

\section{Proof of Theorem 1}

Writing $\sigma_{n}(x)$ for the $(C, 1)$ mean of $\Sigma A_{n}(x)$, we have

$$
\begin{aligned}
\sigma_{n}(x) & =\frac{1}{\pi(n+1)} \int_{0}^{\pi} \phi(t) \sum_{r=0}^{n}\left\{\sin \left(r+\frac{1}{2}\right) t / \sin \frac{1}{2} t\right\} d t \\
& =\frac{1}{\pi(n+1)} \int_{0}^{\pi} \phi(t)\left\{\sin \frac{1}{2}(n+1) t / \sin \frac{1}{2} t\right\}^{2} d t
\end{aligned}
$$

Integrating by parts we get 


$$
\begin{aligned}
\sigma_{n}(x)= & \frac{\Phi_{1}(\pi)}{\pi(n+1)}\left\{\sin \frac{1}{2}(n+1) \pi\right\}^{2}-\frac{1}{2 \pi} \int_{0}^{\pi} \frac{\Phi_{1}(t)}{\sin \frac{1}{2} t} \frac{\sin (n+1) t}{\sin \frac{1}{2} t} d t \\
& \quad+\frac{1}{\pi(n+1)} \int_{0}^{\pi} \frac{\Phi_{1}(t)}{\sin \frac{1}{2} t} \cos \frac{1}{2} t\left\{\sin \frac{1}{2}(n+1) t / \sin \frac{1}{2} t\right\}^{2} d t \\
= & w_{n}+v_{n}+u_{n},
\end{aligned}
$$

say.

Since the $\left(N, p_{n}\right)(C, 1)$ mean of $\Sigma A_{n}(x)$ is the $\left(N, p_{n}\right)$ mean of $\left\{\sigma_{n}(x)\right\}$, in order to prove the theorem it is sufficient to demonstrate that the sequences $\left\{u_{n}\right\},\left\{v_{n}\right\},\left\{w_{n}\right\}$ are summable $\left|N, p_{n}\right|$ under the hypotheses of the theorem.

That $\left\{v_{n}\right\}$ and $\left\{u_{n}\right\}$ are summable $\left|N, p_{n}\right|$, follows directly from our Lemma 3 and Lemma 9, respectively, when we appeal to the hypothesis:

$$
\Phi_{1}(t) / t=\phi_{1}(t) \in \mathrm{BV}(0, \pi) .
$$

Next, we observe that

where

$$
w_{n}-w_{n-1}=\alpha_{n}+\beta_{n},
$$

$$
\begin{aligned}
& \alpha_{n}=\frac{(-1)^{n} A}{n+\frac{1}{2}}=\frac{A \sin \left(n+\frac{1}{2}\right) \pi}{n+\frac{1}{2}} ; \\
& \beta_{n}= \begin{cases}\frac{-A}{2\left(n+\frac{1}{2}\right)(n+1)} & (n \text { even }) ; \\
\frac{-A}{2 n\left(n+\frac{1}{2}\right)} & (n \text { odd }) ;\end{cases}
\end{aligned}
$$

and $A=\Phi_{1}(\pi) / \pi$.

That $\Sigma \alpha_{n}$ is summable $\left|N, p_{n}\right|$, follows as a special case of Lemma 2, while the $\left|N, p_{n}\right|$ summability of $\Sigma \beta_{n}$, follows from its absolute convergence, when we appeal to Lemma 10 .

This completes the proof of Theorem 1.

\section{Proof of Theorem 2}

If $s_{n}^{1}(x)$ denotes the $n$th partial sum of the derived series (1.6), then

$$
s_{n}^{1}(x)=-\frac{1}{\pi} \int_{0}^{\pi} \psi(t) \frac{d}{d t}\left\{\sin \left(n+\frac{1}{2}\right) t / \sin \frac{1}{2} t\right\} d t
$$

and therefore the $(C, 1)$ mean of $\left\{s_{n}^{1}(x)\right\}$ is

$$
\sigma_{n}^{1}(x)=-\frac{1}{\pi(n+1)} \int_{0}^{\pi} \psi(t) \frac{d}{d t}\left\{\sin \frac{1}{2}(n+1) t / \sin \frac{1}{2} t\right\}^{2} d t
$$




$$
\begin{aligned}
= & -\frac{1}{2 \pi} \int_{0}^{\pi} \frac{\psi(t)}{\sin \frac{1}{2} t}\left\{\sin (n+1) t / \sin \frac{1}{2} t\right\} d t \\
& +\frac{1}{\pi(n+1)} \int_{0}^{\pi} \frac{\psi(t)}{\sin \frac{1}{2} t} \cos \frac{1}{2} t\left\{\sin \frac{1}{2}(n+1) t / \sin \frac{1}{2} t\right\}^{2} d t .
\end{aligned}
$$

Following the technique of proof of Theorem 1, we observe that the hypothesis $\psi(t) / t=g(t) \in \mathrm{BV}(0, \pi)$ is sufficient to ensure the $\left|N, p_{n}\right|$ summability of $\left\{\sigma_{n}^{1}(x)\right\}$, by virtue of Lemma 3 and Lemma 9 .

This completes the proof of Theorem 2 .

\section{References}

[1] Max Astrachan, 'Studies in the summability of Fourier series by Nörlund means', Duke Math. J. 2 (1936), 543-569.

[2] L. S. Bosanquet, 'The absolute Cesàro summability of a Fourier series', Proc. London. Math. Soc. 41 (1936), 517-528.

[3] H. P. Dikshit, 'Absolute summability of a Fourier series by Nörlund means', Math. Z. 102 (1967), 166-170.

[4] - A note on a theorem of Astrachan on the $\left(N, p_{n}\right)(C, 1)$ summability of a Fourier series', Math. Student 33 (1964), 71-79.

[5] _ 'On the absolute Nörlund summability of a Fourier series and its conjugate series', Kädai Math. Sem. Rep. 20 (1968), 448-453.

[6] E. Hille and J. D. Tamarkin, 'On the summability of Fourier series I', Trans. Amer. Math. Soc. 34 (1932), 757-783.

[7] J. M. Hyslop, 'On the absolute summability of the successively derived series of Fourier series and its allied series', Proc. London Math. Soc. 46 (1940), 55-80.

[8] E. Kogbetliantz, 'Sur les séries absolument sommable par la méthode des moyennes arithmétique', Bull. des Sc. Math. 49 (1925), 234-256.

[9] B. Kwee, 'Absolute regularity of the Nörlund means', J. Aust. Math. Soc. 5 (1965), 1-7.

[10] F. M. Mears, 'Some multiplication theorems for the Nörlund means,' Bull. Amer. Math. Soc. 41 (1935), 875-880.

[11] N. E. Nörlund, 'Sur une application des fonctions permutables,' Lunds Univ. Arss., 16 (1919), No. 3.

[12] T. Pati, 'On the absolute Nörlund summability of a Fourier series,' J. London. Math. Soc. 34 (1959), 153-160; Addendum: J. London Math. Soc. 37 (1962), 256.

[13] — 'On the absolute summability of a Fourier series by Nörlund means,' Math. Z. 88 (1965), 244-249.

[14] W. Si-Lei, 'On the absolute Nörlund summability of a Fourier series and its conjugate series', Acta Math. Sinica 15 (1965), 281-295.

[15] O. P. Varshney, 'On the absolute Nörlund summability of a Fourier series', Math. Z. 83 (1964), 18-24.

Department of Post-Graduate Studies and Research in Mathematics

University of Jabalpur

Jabalpur (India) 